\title{
Association of Oral Health with Multimorbidity among Older Adults: Findings from the Longitudinal Ageing Study in India, Wave-1, 2017-2019
}

\author{
Srikanta Kanungo ${ }^{1,+}{ }^{+}$, Shishirendu Ghosal ${ }^{1,+}{ }^{\oplus}$, Sushmita Kerketta ${ }^{1}{ }^{\circ}$, Abhinav Sinha ${ }^{2}$, Stewart W Mercer ${ }^{3}$, \\ John Tayu Lee ${ }^{4,5}$ and Sanghamitra Pati ${ }^{1, *(1)}$
}

check for

updates

Citation: Kanungo, S.; Ghosal, S.; Kerketta, S.; Sinha, A.; Mercer, S.W.; Lee, J.T.; Pati, S. Association of Oral Health with Multimorbidity among Older Adults: Findings from the Longitudinal Ageing Study in India, Wave-1, 2017-2019. Int. J. Environ. Res. Public Health 2021, 18, 12853. https://doi.org/10.3390/ ijerph182312853

Academic Editor: Paul B. Tchounwou

Received: 22 October 2021

Accepted: 3 December 2021

Published: 6 December 2021

Publisher's Note: MDPI stays neutral with regard to jurisdictional claims in published maps and institutional affiliations.

Copyright: (c) 2021 by the authors. Licensee MDPI, Basel, Switzerland. This article is an open access article distributed under the terms and conditions of the Creative Commons Attribution (CC BY) license (https:/ / creativecommons.org/licenses/by/ $4.0 /)$.
1 Division of Public Health, ICMR-Regional Medical Research Centre, Department of Health Research, Bhubaneswar 751023, India; srikantak109@gmail.com (S.K.); shishirendu123@gmail.com (S.G.); sushmita.kerketta07@gmail.com (S.K.)

2 Health Technology Assessment in India (HTAiN), ICMR-Regional Medical Research Centre, Department of Health Research, Bhubaneswar 751023, India; dr.abhinav17@gmail.com

3 Usher Institute, College of Medicine and Veterinary Medicine, University of Edinburgh, Edinburgh EH16 4TJ, UK; Stewart.Mercer@ed.ac.uk

4 The Nossal Institute for Global Health, Melbourne School of Population and Global Health, The University of Melbourne, Melbourne, VIC 3010, Australia; johntayulee@unimelb.edu.au

5 Public Health Policy Evaluation Unit, Department of Primary Care and Public Health, School of Public Health, Imperial College London, London SW7 2AZ, UK

* Correspondence: drsanghamitra12@gmail.com

+ Authors with equal contribution.

\begin{abstract}
India is witnessing an increase in the prevalence of multimorbidity. Oral health is related to overall health but is seldom included in the assessment of multimorbidity. Hence, this study aimed to estimate the prevalence of oral morbidity and explore its association with physical multimorbidity using data from Longitudinal Ageing Study in India (LASI). LASI is a nationwide survey amongst adults aged $\geq 45$ years conducted in 2018. Descriptive analysis was performed on included participants $(n=59,764)$ to determine the prevalence of oral morbidity. Multivariable logistic regression assessed the association between oral morbidity and physical multimorbidity. Self-rated health was compared between multimorbid participants with and without oral morbidity. Oral morbidity was prevalent in $48.56 \%$ of participants and physical multimorbidity in $50.36 \%$. Those with multimorbidity were at a higher risk of having any oral morbidity (AOR: 1.60 (1.48-1.73)) than those without multimorbidity. Participants who had only oral morbidity rated their health to be good more often than those who had physical multimorbidity and oral morbidity (40.84\% vs. $32.98 \%)$. Oral morbidity is significantly associated with physical multimorbidity. Multimorbid participants perceived their health to be inferior to those with only oral morbidity. The findings suggest multidisciplinary health teams in primary care should include the management of oral morbidity and physical multimorbidity.
\end{abstract}

Keywords: ageing; India; multimorbidity; oral health; LASI Wave-1

\section{Introduction}

India is currently witnessing a demographic transition with a rapid rise in the ageing population, due to socio-economic and healthcare advancements in the last two decades [1]. Projections suggest that the number of adults aged 60 years and above in India will rise to around 319 million by 2050 which will be approximately $20 \%$ of the national population [2]. This group has complex social, health, and economic needs which will have a major impact on the already overburdened healthcare delivery system.

Oral morbid conditions, such as dental caries and periodontitis, are one of the major public health challenges worldwide amongst disadvantaged people, especially in low- and middle-income countries (LMICs) [3]. The 'Global Burden of Oral Conditions in 1990-2010', 
derived from The Global Burden of Disease (GBD) 2010 study, suggests 3.9 billion people have oral morbidities globally [4]. The factors which directly contribute to poor oral health are lifestyle-related risk factors, along with limited availability and accessibility of services for oral health [5]. Additionally, chronic conditions may be related, as both share common risk factors [6]. Studies have described a bi-directional relationship between diabetes and periodontitis, i.e., people with diabetes often have severe gum disease and vice versa [7]. Periodontal diseases are also associated with increased risk of heart disease, stroke, and respiratory conditions such as pneumonia and chronic obstructive pulmonary disease (COPD) $[8,9]$.

The term multimorbidity refers to the existence of two or more long-term conditions in a single individual [10]. These chronic conditions can either be non-communicable diseases (NCDs) of long duration such as hypertension, long-term mental health conditions such as a mood disorder, or infectious diseases of chronic nature. The prevalence of multimorbidity increases with age; most elderly people develop several NCDs and other health challenges such as degenerative changes, frailty, and mental and cognitive disorders [11]. In LMICs such as India, the demographic transition has increased the prevalence of multimorbidity as estimated by our previous study in primary care which identified multimorbidity to be common among older people, with the prevalence varying from $25 \%$ to $44.4 \%$ among adults aged 45 years and above [12].

Despite the increasing prevalence of multimorbidity, little is known about the association between oral morbidities and physical multimorbidity in India. Even though multimorbidity is increasing, current interventions and clinical practices commonly focus only on single physical conditions rather than multimorbidity including oral conditions [13]. However, the recent Ayushman Bharat scheme envisages providing basic oral healthcare through health and wellness centres being established throughout the country. With increasing life expectancy, policymakers need evidence-based information to understand the need to address both oral issues while focusing on other chronic conditions simultaneously. Hence, this study was carried out to address the present research gap with an aim to estimate the prevalence of oral morbidities and investigate correlates of oral health conditions and explore their association with physical multimorbidity among older adults aged 45 years and above in India using nationally representative data from Longitudinal Ageing Study in India (LASI), Wave-1.

\section{Materials and Methods}

\subsection{Data Source}

This study was based on the data from the Longitudinal Ageing Study in India (LASI), Wave-1, a nationwide survey to scientifically investigate health and its social determinants and related economics. It was conducted by Harvard TH Chan School of Public Health, the International Institute for Population Sciences (IIPS), and the University of Southern California. The data collection across the country spanned from April 2017 to December 2018 following a multistage stratified area probability cluster sampling to identify the unit of observation, i.e., LASI-eligible household (LEH) comprising one or more persons residing in a house with a cooking facility with at least one member aged $\geq 45$ years. Data were collected from all 29 states and 6 Union territories of India following a three-stage sampling design for rural areas and a four-stage sampling for urban areas (Appendix A.1). Eligible candidates from selected households were given a survey instrument that had three segments—namely, Household Survey Schedule, Individual Survey Schedule, and Community Survey Schedule. Information for the Household Survey Schedule was collected from one or more adults who were aware of the socio-demographic status, financial details, water supply, sanitation, etc. of the household. Through the Individual Survey Schedule, the details of the consenting older adult (aged $\geq 45$ years) and their spouses irrespective of age (if applicable) were recorded. The detailed methods of LASI Wave-1 have been reported on the website of the International Institute for Population Sciences (IIPS), Mumbai [14]. 


\subsection{Study Participants and Sample Size}

During the survey, 44,462 age-eligible households were identified, and among them, 72,250 individuals completed the interview from 42,949 households. We excluded participants with missing/wrongly entered/invalid data based on the outcome or independent variables that were used for analysis. Following this, 59,764 participants aged $\geq 45$ years formed our study population. In India, the onset of NCDs is a decade earlier than in the high-income countries due to which this age group was selected for this study [15].

\subsection{Ethical Considerations}

LASI received ethical clearance from the Indian Council of Medical Research (ICMR) and IIPS, Mumbai. This study was based on anonymous secondary data obtained from LASI Wave-1, and hence, there was no risk to participation. The data were requested from IIPS, Mumbai, through proper channels, and appropriate permission was taken. The same has been properly acknowledged and referenced wherever required.

\subsubsection{Variables \\ Oral Morbidity}

The Individual Survey Schedule consisted of self-reported health conditions, along with other socio-demographic details. Participants were asked if they were diagnosed with any one or multiple of the seven specific oral conditions such as, 'painful teeth', 'ulcers lasting more than two weeks', 'bleeding gums', 'swelling gums', 'loose teeth', 'dental cavity/dental caries', 'soreness or cracks in the corner of the mouth' and/or any other conditions in the last one year. Other conditions were reported by 51 participants which were 'not good teeth', 'germs problem', 'root canal', 'heaviness in tongue', 'mouth problem', etc. which was irrelevant, hence were not included in the analysis. We segregated the responses and stratified them into four categories-'none', 'one oral condition', 'two oral conditions' and '>two oral conditions' - to find out the prevalence of oral conditions across different socio-demographic attributes. Further, we classified oral conditions based on soft tissue and hard tissue conditions (Appendix A.4).

\subsection{Exposure Characteristics \\ Socio-Demographic Characteristics}

This included information of the respondents such as age, gender, residence (ru$\mathrm{ral} / \mathrm{urban}$ ), caste (four categories), educational qualification (five categories), employment status (currently working and not working), wealth index (five quantiles), and if the respondent is currently living with his/her partner.

For analysis, we grouped age into three categories, i.e., '45-59 years', '60-74 years', and '75 years and above'. We stratified educational qualification into four categories as follows: 'no formal education' for those who never attended school; 'up to primary school', combining two groups of 'less than primary' and 'primary completed'; the next group was 'middle school to higher secondary' that consisted of three groups of 'middle school completed', 'secondary school/matriculation completed' and 'higher secondary/intermediate/senior'; and lastly, all the remaining groups, 'diploma and certificate holders' 'graduate degree', 'post-graduate degree', and 'professional course/degree' were added together for our final category, 'diploma, graduate, and above'. Further, participants were grouped based on their marital status, who had a life partner ('currently married' and 'live in a relationship') and those who did not have ('divorced' + 'separated' + 'deserted' + 'widowed' + 'never married') presently. States and UTs of the country were divided into six regions east, west, north, south, and northeast. First, three strata of 'caste' were adopted as it was from the data. A new category, 'others' was created merging 'none of them' and 'no caste/tribe'. Individuals, who were 'not working currently' and 'did not work for a minimum of 3 months in a lifetime' were treated as 'currently not working', whereas 'currently working' members were labelled as in the original data. Participants were asked to rate their health in general, 
and the answer of each individual was on a five-point Likert scale mentioned as excellent, very good, good, fair, and poor.

\subsection{Multimorbidity}

During data collection, details of 12 types of self-reported chronic physical diseases and conditions (hypertension, diabetes, cancer, chronic lung disease, chronic heart disease, stroke, arthritis and osteoporosis or other bone/joint diseases, neurological or psychiatric problems, hypercholesterolemia, thyroid disease, gastrointestinal problems, chronic renal disease) and four other morbid conditions (skin diseases, vision and hearing defect, and obesity) were collected. Obesity was assessed on the basis of body mass index (BMI) calculated from height and weight using reference cutoff for the Asian population [16]. In alignment with our objective, we categorised multimorbidity into two groups as physical multimorbidity absent (those who did not have any of the conditions or had only one condition) and physical multimorbidity present (those who had two or more conditions). Additionally, we have also classified these chronic conditions on the basis of body systems following chapters from the International Classification of Diseases (ICD)-10 (Appendix A.4).

\subsection{Data Management and Analysis}

We calculated the mean and standard deviation for the continuous data (age). We also analysed profiles of various diseases among both genders and expressed them in numbers and proportions. Distribution of the number of oral morbidities in relation to other categorical variables (such as age group, gender, area of residence, educational qualification, life partner, caste, employment status, national region, and wealth index) was presented as frequencies $(\mathrm{n}, \mathrm{n} \%)$ and $p$-value. $p$-value less than 0.05 was considered statistically significant. Multivariate logistic regression was performed, expressed as adjusted odds ratio (AOR) with $95 \%$ confidence interval (CI). We separately analysed the proportion of multimorbid participants with and without oral conditions, rating their health status expressed with a significance value obtained from the Mantel Haenszel chi-square test.

\section{Results}

The number of included participants was 59,764 with an age range from 45 years to 116 years and a mean age of $60.22( \pm 10.64)$ years (Table 1$)$. Almost two-thirds of the participants were from rural areas $(69.87 \%)$, with just about one-third $(30.13 \%)$ from urban areas. Almost half $(49.79 \%)$ of the participants were $45-59$ years of age. Participants from different socio-economic groups were almost equally distributed. Gender distribution was also almost equal, with $45.86 \%$ males and $54.14 \%$ females. Almost half $(48.56 \%)$ of the participants had at least one oral morbidity, whereas a higher number of participants $(50.36 \%)$ had physical multimorbidity. The prevalence and association of oral morbidity with various socio-demographic correlates are described in the Appendix A.2. The detailed distribution of various physical chronic conditions across gender is described in the Appendix A.3.

Multivariate regression analysis showed a higher probability of having any oral morbidity among those 60-74 years old than 75 years and above, with AOR 1.27 (1.18-1.37) and 1.02 (0.90-1.16), respectively, as compared with the participants aged 45-59 years (Table 2). Similar chances of having oral morbidity were observed among the rural population (AOR 1.06 (0.97-1.15)), as compared with their urban counterparts. There was a small difference in having oral morbidity among females (AOR $1.13(1.05-1.22)$ ), as compared with males. The highest likelihood of having oral morbidity (AOR $1.22(1.09-1.38)$ ) was reported among the most affluent class, as compared with the participants of other wealth quantiles. 
Table 1. Socio-demographic characteristics of study population.

\begin{tabular}{|c|c|}
\hline Attributes & $n(\%)$ \\
\hline \multicolumn{2}{|c|}{ Age $(n=59,764)$} \\
\hline \multicolumn{2}{|c|}{ Mean ( \pm SD): 60.22 ( \pm 10.64$)$ years, Range: 45 to 116 years. } \\
\hline $45-59$ & $29,756(49.79)$ \\
\hline $60-74$ & $23,539(39.39)$ \\
\hline$\geq 75$ & $6469(10.82)$ \\
\hline \multicolumn{2}{|c|}{ Gender $(n=59,764)$} \\
\hline Male & $27,405(45.86)$ \\
\hline Female & $32,359(54.14)$ \\
\hline \multicolumn{2}{|c|}{ Residence $(n=59,764)$} \\
\hline Rural & $41,759(69.87)$ \\
\hline Urban & $18,005(30.13)$ \\
\hline \multicolumn{2}{|c|}{ Regions of India $(n=59,764)$} \\
\hline North & 4649 (7.78) \\
\hline Central & $15,461(25.87)$ \\
\hline East & $14,180(23.73)$ \\
\hline Northeast & $2054(3.44)$ \\
\hline West & $9452(15.82)$ \\
\hline South & $13,968(23.37)$ \\
\hline \multicolumn{2}{|c|}{ Caste $(n=59,275)$} \\
\hline SC & $11,547(19.48)$ \\
\hline ST & $5113(8.63)$ \\
\hline $\mathrm{OBC}$ & $27,162(45.83)$ \\
\hline Others & $15,452(26.07)$ \\
\hline
\end{tabular}

Educational Qualification $(n=59,763)$

\begin{tabular}{|c|c|}
\hline No formal Education & $30,375(50.82)$ \\
\hline Up to Primary school & $13,925(23.30)$ \\
\hline Middle school to Higher Secondary & $12,342(20.65)$ \\
\hline Diploma, Graduate, and Above & $3122(5.22)$ \\
\hline \multicolumn{2}{|c|}{ Employment Status $(n=59,760)$} \\
\hline Currently working & $27,926(46.73)$ \\
\hline Currently not working & $31,834(53.27)$ \\
\hline \multicolumn{2}{|c|}{ Life Partner $(n=59,762)$} \\
\hline Have a partner & $44,326(74.17)$ \\
\hline Does not have a partner & $15,436(25.83)$ \\
\hline \multicolumn{2}{|c|}{ Wealth Index $(n=59,764)$} \\
\hline The most deprived quantile & $12,615(21.11)$ \\
\hline 2nd quantile & $12,715(21.27)$ \\
\hline 3rd quantile & $12,210(20.43)$ \\
\hline 4th quantile & $11,725(19.62)$ \\
\hline The most affluent quantile & $10,499(17.57)$ \\
\hline
\end{tabular}


Table 2. Multivariate analysis between oral morbidity and its correlates.

\begin{tabular}{|c|c|c|c|}
\hline \multicolumn{2}{|c|}{ Correlates } & \multicolumn{2}{|c|}{ Oral Morbidity } \\
\hline Morbidity & Categories & $\begin{array}{l}\text { AOR (95\% } \\
\text { Confidence } \\
\text { Interval) }\end{array}$ & $p$-Value \\
\hline \multirow{3}{*}{ Age $(n=59,764)$} & $45-59$ & \multicolumn{2}{|c|}{ Reference } \\
\hline & $60-74$ & $1.27(1.18-1.37)$ & $<0.001$ \\
\hline & $\geq 75$ & $1.02(0.90-1.16)$ & 0.701 \\
\hline \multirow{2}{*}{ Gender $(n=59,764)$} & Male & \multicolumn{2}{|c|}{ Reference } \\
\hline & Female & $1.13(1.05-1.22)$ & $<0.001$ \\
\hline \multirow{2}{*}{ Residence $(n=59,764)$} & Rural & $1.06(0.97-1.15)$ & 0.216 \\
\hline & Urban & \multicolumn{2}{|c|}{ Reference } \\
\hline \multirow{6}{*}{ Regions of India $(n=59,764)$} & North & $1.38(1.26-1.52)$ & $<0.001$ \\
\hline & Central & $1.19(1.09-1.30)$ & $<0.001$ \\
\hline & East & $1.52(1.39-1.67)$ & $<0.001$ \\
\hline & Northeast & $1.21(1.09-1.34)$ & $<0.001$ \\
\hline & South & $2.00(1.77-2.26)$ & $<0.001$ \\
\hline & West & \multicolumn{2}{|c|}{ Reference } \\
\hline \multirow{4}{*}{ Caste $(n=59,275)$} & SC & \multicolumn{2}{|c|}{ Reference } \\
\hline & ST & $1.06(0.95-1.18)$ & 0.298 \\
\hline & OBC & $1.05(0.97-1.14)$ & 0.192 \\
\hline & Others & $1.00(0.92-1.09)$ & 0.980 \\
\hline \multirow{4}{*}{ Educational Qualification $(n=59,763)$} & No formal Education & $1.84(1.44-2.36)$ & $<0.001$ \\
\hline & Up to Primary school & $1.71(1.33-2.20)$ & $<0.001$ \\
\hline & Middle school to Higher Secondary & $1.49(1.14-1.94)$ & 0.004 \\
\hline & Diploma, Graduate, and Above & \multicolumn{2}{|c|}{ Reference } \\
\hline \multirow{2}{*}{ Employment Status $(n=59,760)$} & Currently working & $0.93(0.86-1.00)$ & 0.052 \\
\hline & Currently not working & \multicolumn{2}{|c|}{ Reference } \\
\hline \multirow{2}{*}{ Life Partner $(n=59,762)$} & Have a Partner & $1.06(0.97-1.16)$ & 0.185 \\
\hline & Do not have a Partner & \multicolumn{2}{|c|}{ Reference } \\
\hline \multirow{5}{*}{ Wealth Index $(n=59,764)$} & The most deprived quantile & \multicolumn{2}{|c|}{ Reference } \\
\hline & 2nd quantile & $1.10(1.01-1.20)$ & 0.038 \\
\hline & 3rd quantile & $1.13(1.02-1.25)$ & 0.017 \\
\hline & 4th quantile & $1.12(1.01-1.24)$ & 0.036 \\
\hline & The most affluent quantile & $1.22(1.09-1.38)$ & 0.001 \\
\hline \multirow{2}{*}{$\begin{array}{l}\text { Multimorbidity } \\
\quad(n=59,764)\end{array}$} & Absent & \multicolumn{2}{|c|}{ Reference } \\
\hline & Present & $1.60(1.48-1.73)$ & $<0.001$ \\
\hline
\end{tabular}

A higher likelihood of having oral morbidity was found to be associated with lesser educational qualification. Respondents who never went to school had higher odds (AOR 1.84 (1.44-2.36)) of having oral morbidity, as compared with those having diplomas, graduate degrees, and above. We found that the prevalence of oral morbidity increased with the presence of multimorbidity, and there was a higher likelihood (AOR $1.60(1.48-1.73)$ ) of having oral morbidity in patients who had physical multimorbidity, as compared with those who did not have multimorbidity. Similarly, increased numbers of physical chronic 
conditions within individuals were associated with a higher likelihood of having oral morbidities (Figure 1). A high proportion (16.6\%) of the participants who had two physical chronic conditions reported to have two oral morbidities which increased to $17.8 \%$ among participants with three or more chronic conditions. Multimorbid individuals had a greater burden of oral morbidity which also tended to rise with an increase in the number of physical chronic conditions.

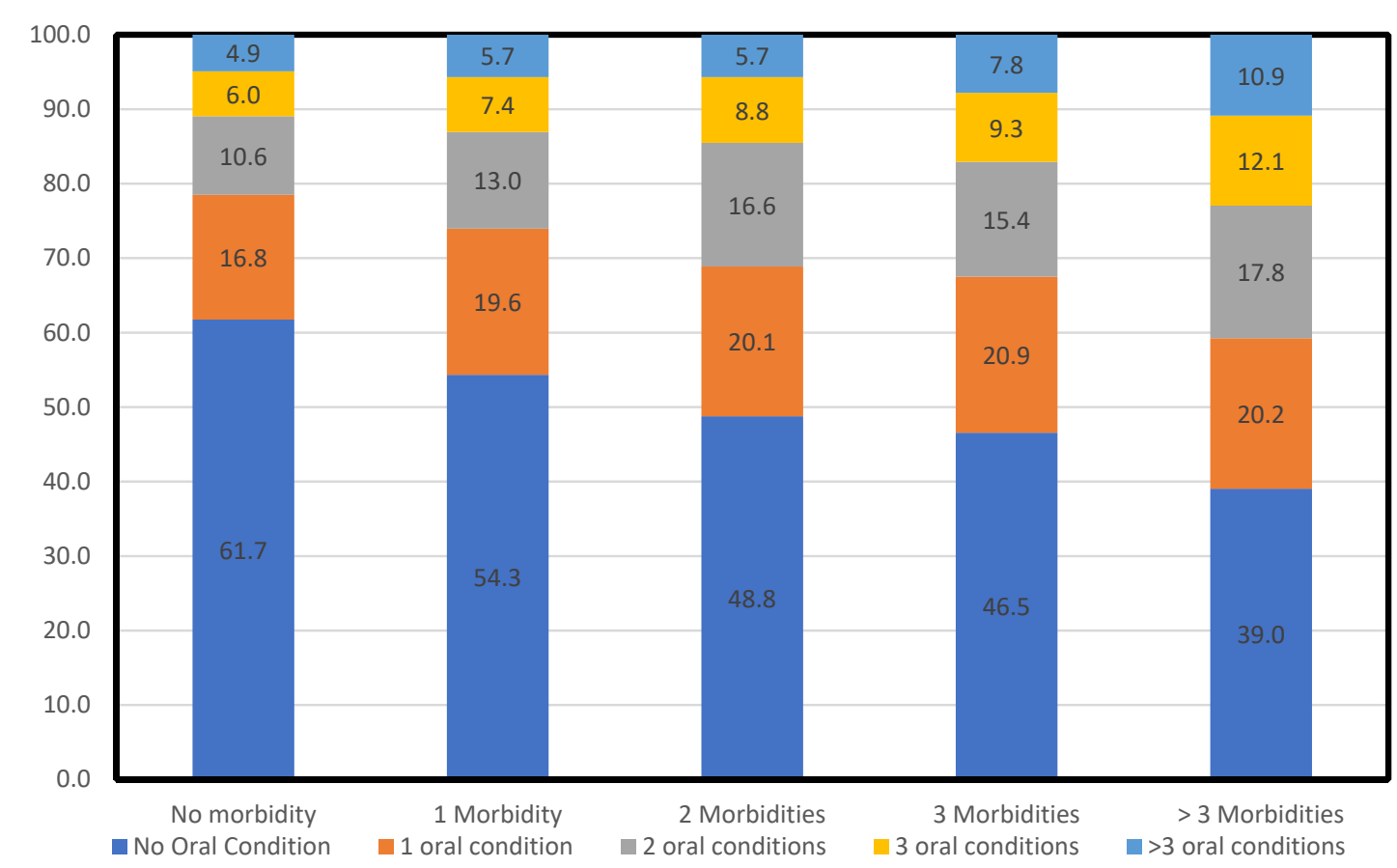

Figure 1. Relationship between count of multimorbidity and oral morbidity.

A higher number of participants who had only oral morbidity rated their overall health to be excellent $(3.87 \%)$, very good $(18.38 \%)$, and good $(40.84 \%)$ than those who had physical multimorbidity along with oral morbidity, who rated their health to be excellent $(2.32 \%)$, very good (11.62\%), and good (32.98\%) (Table 3). Further, we described the frequency of oral conditions grouped as soft tissue and hard tissue across physical conditions classified on the basis of various body systems (Appendix A.4). We found soft tissue conditions were common among patients with circulatory conditions $(40.14 \%)$, whereas hard tissue conditions were common among individuals with conditions of endocrine, nutritional, and metabolic conditions $(40.45 \%)$.

Table 3. Self-rated health among multimorbid participants with and without oral morbidity.

\begin{tabular}{|c|c|c|c|c|c|}
\hline \multirow{3}{*}{ Self-Rated Health } & \multicolumn{4}{|c|}{ Oral Morbidity $(n=59,745)$} & \multirow{3}{*}{$\begin{array}{c}\text { Mantel Haenszel } \\
\text { Chi-Square Test } \\
\\
p \text {-Value }\end{array}$} \\
\hline & \multicolumn{2}{|c|}{ Present } & \multicolumn{2}{|c|}{ Absent } & \\
\hline & $\begin{array}{c}\text { Multimorbidity } \\
\text { Present } \\
n, \%(\mathrm{CI})\end{array}$ & $\begin{array}{c}\text { Multimorbidity Absent } \\
n, \% \text { (CI) }\end{array}$ & $\begin{array}{c}\text { Multimorbidity } \\
\text { Present } \\
n, \%(\mathrm{CI})\end{array}$ & $\begin{array}{c}\text { Multimorbidity Absent } \\
n, \%(C I)\end{array}$ & \\
\hline Excellent & $382,2.32(2.10-2.56)$ & $486,3.87(3.53-4.22)$ & $549,4.03(3.70-4.37)$ & $1058,6.20(5.84-6.57)$ & \\
\hline Very Good & $1912,11.62(11.14-12.12)$ & $2312,18.38(17.71-19.07)$ & $2269,16.64(16.01-17.27)$ & $3974,23.27(22.64-23.92)$ & \\
\hline Good & $5425,32.98(32.26-33.71)$ & $5138,40.84(39.99-41.71)$ & $4592,33.66(32.87-34.46)$ & $7295,42.72(41.98-43.47)$ & $<0.001$ \\
\hline Fair & $5960,36.23(35.50-36.98)$ & $3636,28.90(28.12-29.71)$ & $4354,31.92(31.13-32.71)$ & $3794,22.22(21.60-22.85)$ & \\
\hline Poor & $2770,16.84(16.27-17.42)$ & $1007,8.01(7.54-8.49)$ & $1878,13.76(13.19-14.36)$ & $955,5.59(5.25-5.95)$ & \\
\hline
\end{tabular}




\section{Discussion}

Using the nationally representative data of India, we found a high prevalence of physical multimorbidity and oral morbidity among older adults. A key finding of this study was the increased chance of having oral morbidity among multimorbid individuals, who also rated their health to be compromised more, as compared with their counterparts who did not have oral morbidity. Our study estimated a $48 \%$ prevalence of oral morbidity among adults aged 45 years and above, but various studies have reported different prevalence, depending on the age group and number of oral conditions observed. A similar study conducted in New Delhi reported a $91.9 \%$ prevalence of dental caries among adults aged $\geq 60$ years [17] which is higher than the findings of our study; conversely, in contrast to our findings, a study conducted among rural Indian adults aged 35-54 years reported a 13\% prevalence of one or more oral health impacts [18] which is considerably lower than the present study. However, there is a paucity of comprehensive data reporting the exact extent of the burden of oral morbidities in India which could mainly be attributed to considering oral health of almost trivial value.

Ageing often increases risk factors such as cognitive and functional impairment, reduced mobility, and frailty, which hampers the quality of life leading to dependence [19]. These conditions are directly associated with compromised oral health [20]. There has been a substantial increase in multimorbidity among LMICs such as India, mainly attributed to the rise in non-communicable diseases alongside prevailing chronic infectious diseases. Our previous systematic review assessed the prevalence of multimorbidity in South Asia $(4.5 \%$ to $20.8 \%)$ among adults aged 18 years and above which increased among older adults aged 60 years and above $(24.1 \%$ to $83 \%)$ [21]. This indicated multimorbidity to be more akin among the ageing population, hence escalating the risk for compromised oral health. Our study reported $50.36 \%$ of the older adults to have multimorbidity which is consistent with the findings of a multinational study (including India) reporting 56.6\% multimorbidity among adults aged $\geq 50$ years [22]. These long-term chronic conditions of 10 present complex-care needs put a financial burden on the individual; as a result, oral health needs are often overshadowed both for the patients and their caregiving family members [23], as shown by the findings of our study which revealed oral morbidities to be commonly associated with a certain group of physical conditions such as endocrine disorders, visual impairment, and circulatory system diseases. A probable reason for the high frequency of oral conditions among individuals with visual impairment can be their inability to maintain oral hygiene. Further, circulatory system diseases are known to be associated with bleeding and swelling gums (soft tissue) and respiratory conditions [8,9].

A similar study to investigate differences in the distribution of oral health indicators among elderly people with and without multimorbidity observed a significant difference in the prevalence of edentulism among multimorbid participants than those without multimorbidity (53.3\% vs. $32.7 \% . p=0.015$ ) [24] which is consistent with the findings of this study. Inextricably, oral health is related to overall health and quality of life but is seldom included in the assessment of multimorbidity, leading to the scarcity in the available literature. Here, it is worth noting that the available studies were confined to multimorbidity excluding oral conditions, posing a challenge to compare our findings with other similar studies.

Self-rated health (SRH) is regarded as a proxy indicator for quality of life. We found a significant proportion of multimorbid individuals who had oral morbidity rated their health to be poorer than those who did not have any oral morbidity. This could be due to the complex correlation between physical multimorbidity and shared risk factors of ageing which compels individuals to polypharmacy. Polypharmacy further cascades to frailty through weight loss, and exhaustion has poor outcomes such as disability [25]. Furthermore, all these factors club to have an ill effect on general and oral health, leading to decreased self-esteem and affecting mental health and quality of life. A study conducted to find the association between mental and oral health in Spain reported a positive association between the presence of oral conditions and having at least one psychiatric condition [26]. 


\subsection{Implications for Policy and Practice}

Most of the oral conditions are preventable and share risk factors with other physical chronic conditions. Hence, an aim to reduce risk factors such as frequent snacking, sugar consumption, tobacco, and alcohol consumption should be targeted. Awareness regarding oral hygiene should be created from childhood. People should be motivated to equally prioritise oral health similar to other physical chronic conditions, so as to prevent extensive damage and reduce economic burden. Additionally, coordinated quality care as provided by health and wellness centres, under one umbrella, should be aimed. Multidisciplinary teams at primary care should holistically approach patient-centred treatment. Further, longitudinal studies on multimorbidity including oral morbidities are needed to generate evidence on clustering of oral conditions among multimorbid individuals.

\subsection{Strengths and Limitations}

To the best of our knowledge, this is the first study in India to investigate the association of oral morbidity with physical multimorbidity. The main strong point of our study lies in the use of nationally representative data captured using rigorous scientific methodology. LASI takes into account self-reported health conditions which were used to determine physical multimorbidity, a limitation for this study. Various correlates such as smoking, alcohol, and sugar intake which affect both oral and general health could not be analysed due to insufficient data.

\section{Conclusions}

This study suggested a high burden of oral morbidity which is significantly associated with multimorbidity. Furthermore, multimorbid participants with oral morbidity perceived their health to be more compromised than those having only oral morbidity. The findings of this study suggest the inclusion of oral healthcare services in primary care settings while managing physical multimorbidity. Additionally, future studies to establish linkages between physical multimorbidity and oral morbidity are warranted.

Author Contributions: Conceptualization, S.P., S.K. (Srikanta Kanungo) and S.G.; methodology, S.P., S.K. (Srikanta Kanungo), S.G., A.S., S.K. (Sushmita Kerketta), S.W.M. and J.T.L.; software, S.K. (Srikanta Kanungo); formal analysis, S.G., S.K. (Sushmita Kerketta) and A.S.; data curation, S.P.; writing — original draft preparation, S.G., S.K. (Sushmita Kerketta) and A.S.; writing-review and editing, S.P., S.K. (Srikanta Kanungo), S.W.M. and J.T.L.; supervision, S.P. All authors have read and agreed to the published version of the manuscript.

Funding: This research received no external funding.

Institutional Review Board Statement: Not applicable.

Informed Consent Statement: Not applicable.

Data Availability Statement: The dataset analysed during the current study is available in the LASI data repository at ICT, IIPS (https:/ /iipsindia.ac.in/content/lasi-wave-i (accessed on 22 January 2021)).

Acknowledgments: The authors are grateful to the Longitudinal Ageing Study in India (LASI), for assembling and publishing accurate, nationally representative data on a range of health, biomarkers, and healthcare utilisation indicators for the population in the age range of 45 years and older. The authors are also grateful to LASI's project partners, the International Institute for Population Sciences (IIPS), Harvard T. H. Chan School of Public Health (HSPH), and the University of Southern California (USC).

Conflicts of Interest: The authors declare no conflict of interest.

Ethical Considerations: LASI received ethical clearance from the Indian Council of Medical Research (ICMR) and IIPS, Mumbai. This study was based on anonymous secondary data obtained from LASI Wave-1, and hence, there was no risk to participation. The data were requested from IIPS, Mumbai 
through proper channels, and appropriate permission was taken. The same has been properly acknowledged and referenced wherever required.

\section{Appendix A}

Appendix A.1

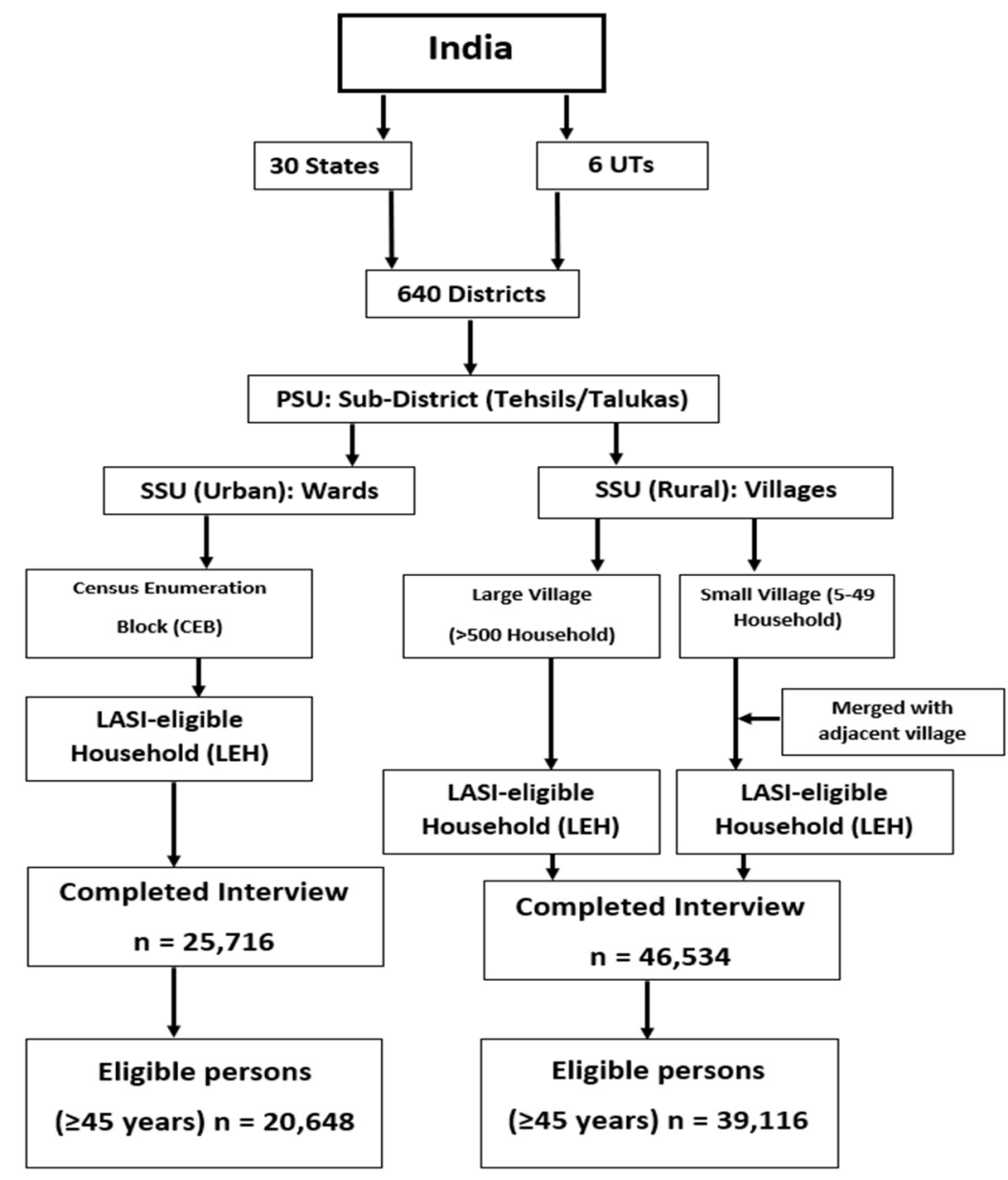

Figure A1. Selection criteria for the study population. Abbreviations used. UT: union territory, PSU: primary secondary unit, SSU: secondary sampling unit, CEB: census enumeration block, LEH: LASI-eligible household.

\section{Appendix A.2}

Table A1. Prevalence of oral morbidity in relation to various socio-demographic characteristics.

\begin{tabular}{cccccc}
\hline \multicolumn{2}{c}{ Socio-Demographic Characteristics } & \multicolumn{3}{c}{ Number of Oral Morbidities } \\
\hline Attributes & Categories & None & One Oral Morbidity & Two Oral Morbidities & $>$ Two Oral Morbidities \\
\hline \multirow{2}{*}{$\begin{array}{c}\text { Age groups } \\
(n=59,764)\end{array}$} & $45-59$ & $16,272,54.69(54.12-55.25)$ & $5437,18.27(17.83-18.72)$ & $3998,13.44(13.05-13.83)$ & $4048,13.60(13.22-14.00)$ \\
\cline { 2 - 6 } & $60-74$ & $11,149,47.36(46.72-48.00)$ & $4780,20.31(19.79-20.83)$ & $3610,15.34(14.88-15.80)$ & $4000,16.99(16.52-17.48)$ \\
\hline \multirow{nyyyyy}{*}{$\begin{array}{c}\text { Gender } \\
(n=59,764)\end{array}$} & Male & $3321,51.34(50.10-52.55)$ & $1362,21.05(20.06-22.07)$ & $925,14.29(13.45-15.17)$ & $862,13.32(12.50-14.18)$ \\
\cline { 2 - 6 } & Female & $14,958,54.58(53.99-55.17)$ & $5114,18.66(18.20-19.13)$ & $3783,13.80(13.40-14.22)$ & $3550,12.95(12.56-13.36)$ \\
\hline
\end{tabular}


Table A1. Cont.

\begin{tabular}{|c|c|c|c|c|c|}
\hline \multicolumn{2}{|c|}{ Socio-Demographic Characteristics } & \multicolumn{4}{|c|}{ Number of Oral Morbidities } \\
\hline Attributes & Categories & None & One Oral Morbidity & Two Oral Morbidities & > Two Oral Morbidities \\
\hline \multirow{2}{*}{$\begin{array}{l}\text { Residence } \\
(n=59,764)\end{array}$} & Rural & $21,427,51.31(50.83-51.79)$ & $8091,19.38(19.00-19.76)$ & $5771,13.82(13.49-14.15)$ & $6470,15.49(15.15-15.84)$ \\
\hline & Urban & $9315,51.74(51.00-52.47)$ & $3488,19.37(18.80-19.96)$ & $2763,15.34(14.82-15.88)$ & $2439,13.55(13.05-14.05)$ \\
\hline \multirow{6}{*}{$\begin{array}{l}\text { Regions of India } \\
\quad(n=59,764)\end{array}$} & North & $2328,50.08(48.63-51.52)$ & $956,20.56(19.41-21.75)$ & $695,14.94(13.94-16.01)$ & $670,14.41(13.41-15.45)$ \\
\hline & Central & $8803,56.94(56.15-57.72)$ & $2369,15.32(14.76-15.90)$ & $1823,11.79(11.29-12.31)$ & $2466,15.95(15.38-16.54)$ \\
\hline & East & $7015,49.47(48.64-50.30)$ & $2496,17.60(16.98-18.24)$ & $1870,13.19(12.63-13.76)$ & $2799,19.74(19.09-20.40)$ \\
\hline & Northeast & $1162,56.57(54.40-58.73)$ & $332,16.16(14.60-17.83)$ & $344,16.73(15.16-18.43)$ & $216,10.54(9.22-11.92)$ \\
\hline & West & $5587,59.10(58.11-60.10)$ & $1502,15.90(15.16-16.64)$ & $1264,13.38(12.69-14.08)$ & $1099,11.62(10.99-12.29)$ \\
\hline & South & $5847,41.86(41.04-42.68)$ & $3924,28.09(27.35-28.84)$ & $2538,18.17(17.53-18.82)$ & $1659,11.88(11.35-12.43)$ \\
\hline \multirow{4}{*}{$\begin{array}{c}\text { Caste } \\
(n=59,275)\end{array}$} & SC & $6021,52.15(51.23-53.06)$ & $2185,18.92(18.21-19.65)$ & $1516,13.13(12.52-13.76)$ & $1825,15.81(15.14-16.48)$ \\
\hline & ST & $2813,55.03(53.64-56.39)$ & $878,17.17$ (16.15-18.23) & $677,13.24(12.32-14.20)$ & $745,14.57$ (13.61-15.57) \\
\hline & OBC & $13,437,49.47(48.87-50.06)$ & $5581,20.55(20.06-21.03)$ & $4177,15.38$ (14.95-15.81) & $3968,14.61(14.19-15.03)$ \\
\hline & Others & $8247,53.37(52.58-54.16)$ & $2809,18.18(17.57-18.80)$ & $2103,13.61(13.07-14.16)$ & $2293,14.48(14.28-15.41)$ \\
\hline \multirow{4}{*}{$\begin{array}{c}\text { Educational } \\
\text { Qualification } \\
(n=59,763)\end{array}$} & No Formal Education & $15,045,49.53(48.97-50.10)$ & $5939,19.55(19.11-20.00)$ & $4384,14.43(14.04-14.83)$ & $5006,16.48(16.07-16.90)$ \\
\hline & Up to Primary School & $7096,50.96(50.12-51.79)$ & 2801, 20.11 (19.45-20.79) & 2020, 14.51 (13.93-15.10) & $2008,14.42(13.84-15.01)$ \\
\hline & $\begin{array}{l}\text { Middle School to } \\
\text { Higher Secondary }\end{array}$ & $6663,53.99(53.10-54.87)$ & $2332,18.89(18.21-19.60)$ & $1683,13.64(13.04-14.25)$ & $1664,13.48(12.88-14.10)$ \\
\hline & $\begin{array}{l}\text { Diploma, Graduate, } \\
\text { and Above }\end{array}$ & $1937,62.04(60.31-63.75)$ & $508,16.26(14.99-17.61)$ & $445,14.26(13.05-15.53)$ & $232,7.43(6.54-8.41)$ \\
\hline \multirow{2}{*}{$\begin{array}{l}\text { Employment Status } \\
\qquad(n=59,760)\end{array}$} & Currently Working & $15,304,54.80(54.22-55.39)$ & $5098,18.25(17.80-18.71)$ & $3859,13.82(13.42-14.23)$ & $3665,13.12(12.73-13.53)$ \\
\hline & $\begin{array}{l}\text { Currently not } \\
\text { Working }\end{array}$ & $15,435,48.49(47.94-49.04)$ & 6481, $20.36(19.92-20.81)$ & $4674,14.68(14.30-15.08)$ & $5244,16.47(16.07-16.89)$ \\
\hline \multirow{2}{*}{$\begin{array}{l}\text { Life Partner } \\
(n=59,762)\end{array}$} & Have a Partner & $23,133,52.19(51.72-52.65)$ & 8437, 19.04 (18.67-19.40) & $6363,14.35(14.03-14.68)$ & $6393,14.42(14.10-14.75)$ \\
\hline & $\begin{array}{l}\text { Do not Have a } \\
\text { Partner }\end{array}$ & $7608,49.29(48.50-50.08)$ & 3141, 20.34 (19.72-20.99) & $2171,14.07(13.52-14.62)$ & $2516,16.30(15.72-16.89)$ \\
\hline \multirow{5}{*}{$\begin{array}{l}\text { Wealth Index } \\
(n=59,764)\end{array}$} & $\begin{array}{c}\text { The most deprived } \\
\text { quantile }\end{array}$ & $6906,54.73(53.87-55.62)$ & $2354,18.66$ (17.98-19.35) & $1523,12.07(11.51-12.65)$ & $1832,14.52(13.91-15.15)$ \\
\hline & 2nd quantile & $6622,52.09(51.21-52.95)$ & $2359,18.55$ (17.88-19.24) & $1784,14.03(13.43-14.65)$ & $1950,15.33(14.71-15.97)$ \\
\hline & 3rd quantile & $6205,50.82(49.93-51.71)$ & $2539,20.79(20.08-21.53)$ & $1661,13.61(13.00-14.22)$ & $1805,14.78(14.16-15.43)$ \\
\hline & 4th quantile & $5952,50.76(49.85-51.67)$ & 2290, 19.54 (18.82-20.26) & $1745,14.88(14.24-15.54)$ & $1738,14.82(14.18-15.48)$ \\
\hline & $\begin{array}{l}\text { The most affluent } \\
\text { quantile }\end{array}$ & $5056,48.16(47.20-49.12)$ & $2036,19.40(18.64-20.16)$ & $1821,17.34(16.62-18.08)$ & $1586,15.10(14.43-15.81)$ \\
\hline
\end{tabular}

Appendix A.3

Table A2. Distribution of various physical chronic conditions in relation to gender.

\begin{tabular}{|c|c|c|c|c|c|}
\hline \multirow{2}{*}{ Chronic Conditions } & \multicolumn{2}{|c|}{ Male } & \multicolumn{2}{|c|}{ Female } & \multirow{2}{*}{$\begin{array}{c}\text { Total } \\
(n, 100 \%)\end{array}$} \\
\hline & $n(\%)$ & $95 \% \mathrm{CI}$ & $n(\%)$ & $95 \%$ CI & \\
\hline Hypertension $(n=59,745)$ & $6242(38.47)$ & $(37.72-39.22)$ & $9984(61.53)$ & $(60.78-62.28)$ & 16,226 \\
\hline Diabetes $(n=59,744)$ & $3285(45.90)$ & $(44.75-47.07)$ & $3871(54.10)$ & $(52.93-55.25)$ & 7156 \\
\hline Cancer $(n=59,752)$ & $130(34.66)$ & $(29.85-39.72)$ & $245(65.34)$ & $(60.28-70.14)$ & 375 \\
\hline Chronic Lung Diseases $(n=59,753)$ & $1997(50.31)$ & $(48.75-51.88)$ & $1972(49.69)$ & $(48.12-51.25)$ & 3969 \\
\hline Chronic Heart Diseases $(n=59,753)$ & $1143(49.82)$ & $(47.76-51.89)$ & $1151(50.18)$ & $(48.11-52.24)$ & 2294 \\
\hline Stroke $(n=59,752)$ & $655(59.86)$ & $(56.90-62.79)$ & $439(40.14)$ & $(37.21-43.10)$ & 1094 \\
\hline $\begin{array}{l}\text { Arthritis and Other Bone/Joint } \\
\text { Diseases }(n=59,754)\end{array}$ & $3581(36.54)$ & $(35.59-37.51)$ & $6218(63.46)$ & $(62.49-64.41)$ & 9799 \\
\hline
\end{tabular}


Table A2. Cont.

\begin{tabular}{|c|c|c|c|c|c|}
\hline \multirow{2}{*}{ Chronic Conditions } & \multicolumn{2}{|c|}{ Male } & \multicolumn{2}{|c|}{ Female } & \multirow{2}{*}{$\begin{array}{c}\text { Total } \\
(n, 100 \%)\end{array}$} \\
\hline & $n(\%)$ & $95 \% \mathrm{CI}$ & $n(\%)$ & $95 \% \mathrm{CI}$ & \\
\hline $\begin{array}{l}\text { Neurological and Psychological } \\
\text { Problems }(n=59,745)\end{array}$ & $637(45.83)$ & $(43.18-48.49)$ & $753(54.17)$ & $(51.51-56.82)$ & 1390 \\
\hline Hypercholesterolemia $(n=59,752)$ & $631(45.49)$ & $(42.82-48.12)$ & $757(54.51)$ & $(51.88-57.18)$ & 1388 \\
\hline Chronic Renal Failure $(n=59,764)$ & $224(56.46)$ & $(51.39-61.36)$ & $173(43.54)$ & $(38.64-48.61)$ & 397 \\
\hline Thyroid Disorder $(n=59,764)$ & $338(20.31)$ & $(18.39-22.31)$ & $1327(79.69)$ & $(77.69-81.61)$ & 1665 \\
\hline Gastrointestinal Problems $(n=59,764)$ & $5103(46.80)$ & $(45.85-47.74)$ & $5802(53.20)$ & $(52.26-54.15)$ & 10,905 \\
\hline Skin Diseases $(n=59,764)$ & $1527(49.27)$ & $(47.50-51.05)$ & $1572(50.73)$ & $(48.95-52.50)$ & 3099 \\
\hline Vision Defect $(n=59,756)$ & $13,084(45.59)$ & $(45.01-46.17)$ & $15,614(54.41)$ & $(53.83-54.99)$ & 28,698 \\
\hline Hearing Defect $(n=59,757)$ & $1831(45.73)$ & $(44.17-47.28)$ & $2174(54.27)$ & $(52.72-55.83)$ & 4005 \\
\hline Obesity $(n=59,073)$ & $5783(36.14)$ & $(35.40-36.89)$ & $10,219(63.86)$ & $(63.11-64.61)$ & 16,001 \\
\hline Oral Problems $(n=59,764)$ & $12,448(42.89)$ & $(42.32-43.46)$ & $16,574(57.11)$ & $(56.54-57.68)$ & 29,022 \\
\hline
\end{tabular}

Appendix A.4

Table A3. Distribution of oral morbidities in relation to various chronic conditions grouped under chapters of ICD-10.

\begin{tabular}{ccc}
\hline Disease Groups & $\begin{array}{c}\text { Soft Tissue } \\
\boldsymbol{n}(\mathbf{\%})\end{array}$ & $\begin{array}{c}\text { Hard Tissue } \\
\boldsymbol{( \% )}\end{array}$ \\
\hline Neoplasms & $163(43.52)$ & $189(50.23)$ \\
\hline Endocrine, nutritional and metabolic & $7280(35.36)$ & $8250(40.08)$ \\
\hline Mental and behavioural & $667(47.97)$ & $666(47.91)$ \\
\hline Diseases of the eye and adnexa & $10,852(37.81)$ & $11,608(40.45)$ \\
\hline Ear & $1878(46.90)$ & $2022(50.47)$ \\
\hline Circulatory system & $6961(39.98)$ & $7288(41.86)$ \\
\hline Respiratory system & $1695(42.70)$ & $1893(47.70)$ \\
\hline Digestive system & $4986(45.72)$ & $5336(48.94)$ \\
\hline Skin & $1303(42.05)$ & $1453(46.88)$ \\
\hline Genitourinary & $4704(48.01)$ & $4838(49.38)$ \\
\hline
\end{tabular}

Soft tissue conditions: bleeding gums, swelling gums, oral ulcer, cracked mouth corner, loose tooth; hard tissue conditions: pain tooth, dental caries; neoplasm: cancer; endocrine; nutritional and metabolic: diabetes, thyroid disorders, obesity, hypercholesterolemia; mental and behavioural: neurological and psychological disorders; diseases of the eye and adnexa; ear; circulatory system: chronic heart disease, hypertension, stroke; respiratory system: chronic lung disease; digestive system: gastrointestinal disorders; skin; musculoskeletal: arthritis, osteoporosis, other bone/joint diseases; genitourinary: chronic kidney disease.

\section{References}

1. Panchbhai, A.S. Oral health care needs in the dependant elderly in India. Indian J. Palliat. Care 2012, 18, 19-26. [CrossRef]

2. United Nations. World Population Prospects-Population Division. Available online: https://population.un.org/wpp/ (accessed on 27 November 2021).

3. Petersen, P.E.; Yamamoto, T. Improving the oral health of older people: The approach of the WHO Global Oral Health Programme. Community Dent. Oral Epidemiol. 2005, 33, 81-92. [CrossRef]

4. Marcenes, W.; Kassebaum, N.J.; Bernabé, E.; Flaxman, A.; Naghavi, M.; Lopez, A.; Murray, C.J.L. Global burden of oral conditions in 1990-2010: A systematic analysis. J. Dent. Res. 2013, 92, 592-597. [CrossRef]

5. Sisson, K.L. Theoretical explanations for social inequalities in oral health. Community Dent. Oral Epidemiol. 2007, 35, 81-88. [CrossRef]

6. Griffin, S.O.; Barker, L.K.; Griffin, P.M.; Cleveland, J.L.; Kohn, W. Oral health needs among adults in the United States with chronic diseases. J. Am. Dent. Assoc. 2009, 140, 1266-1274. [CrossRef] 
7. $\quad$ Barnes, V.M.; Kennedy, A.D.; Panagakos, F.; Devizio, W.; Trivedi, H.M.; Jönsson, T.; Guo, L.; Cervi, S.; Scannapieco, F.A. Global metabolomic analysis of human saliva and plasma from healthy and diabetic subjects, with and without periodontal disease. PLoS ONE 2014, 9, e105181. [CrossRef]

8. Pihlstrom, B.L.; Michalowicz, B.S.; Johnson, N.W. Periodontal diseases. Lancet 2005, 366, 1809-1820. [CrossRef]

9. Scannapieco, F.A.; Bush, R.B.; Paju, S. Associations between periodontal disease and risk for nosocomial bacterial pneumonia and chronic obstructive pulmonary disease. A systematic review. Ann. Periodontol. 2003, 8, 54-69. [CrossRef] [PubMed]

10. MacMahon, S. Multimorbidity: A Priority for Global Health Research; The Academy of Medical Sciences: London, UK, 2018.

11. Banerjee, R.; Chahande, J.; Banerjee, S.; Radke, U. Evaluation of relationship between nutritional status and oral health related quality of life in complete denture wearers. Indian J. Dent. Res. 2018, 29, 562-567. [CrossRef]

12. Pati, S.; Swain, S.; Hussain, M.A.; Kadam, S.; Salisbury, C. Prevalence, correlates, and outcomes of multimorbidity among patients attending primary care in Odisha, India. Ann. Fam. Med. 2015, 13, 446-450. [CrossRef]

13. Gambhir, R.; Gupta, T. Need for Oral Health Policy in India. Ann. Med. Health Sci. Res. 2016, 6, 50. [CrossRef]

14. International Institute for Population Sciences (IIPS). Longitudinal Ageing Study in India (LASI). Available online: https: / / www.iipsindia.ac.in/lasi (accessed on 27 November 2021).

15. Arokiasamy, P. India's escalating burden of non-communicable diseases. Lancet Glob. Health 2018, 6, e1262-e1263. [CrossRef]

16. Dhawan, D.; Sharma, S. Abdominal Obesity, Adipokines and Non-communicable Diseases. J. Steroid Biochem. Mol. Biol. 2020, 203, 105737. [CrossRef] [PubMed]

17. Patro, B.; Ravi Kumar, B.; Goswami, A.; Mathur, V.; Nongkynrih, B. Prevalence of dental caries among adults and elderly in an urban resettlement colony of New Delhi. Indian J. Dent. Res. 2008, 19, 95-98.

18. Bhat, M.; Bhat, S.; Brondani, M.; Mejia, G.C.; Pradhan, A.; Roberts-Thomson, K.; Do, L.G. Prevalence, Extent, and Severity of Oral Health Impacts Among Adults in Rural Karnataka, India. JDR Clin. Transl. Res. 2021, 6, 242-250. [CrossRef]

19. Calderón-Larrañaga, A.; Vetrano, D.L.; Ferrucci, L.; Mercer, S.W.; Marengoni, A.; Onder, G.; Eriksdotter, M.; Fratiglioni, L. Multimorbidity and functional impairment—bidirectional interplay, synergistic effects and common pathways. J. Intern. Med. 2019, 285, 255. [CrossRef]

20. van der Putten, G.J.; de Baat, C.; De Visschere, L.; Schols, J. Poor oral health, a potential new geriatric syndrome. Gerodontology 2014, 31, 17-24. [CrossRef]

21. Pati, S.; Swain, S.; Hussain, M.A.; Van Den Akker, M.; Metsemakers, J.; Knottnerus, J.A.; Salisbury, C. Prevalence and outcomes of multimorbidity in South Asia: A systematic review. BMJ Open 2015, 5, e007235. [CrossRef] [PubMed]

22. Stubbs, B.; Vancampfort, D.; Veronese, N.; Schofield, P.; Lin, P.Y.; Tseng, P.T.; Solmi, M.; Thompson, T.; Carvalho, A.F.; Koyanagi, A. Multimorbidity and perceived stress: A population-based cross-sectional study among older adults across six low- and middle-income countries. Maturitas 2018, 107, 84-91. [CrossRef] [PubMed]

23. Watt, R.G.; Serban, S. Multimorbidity: A challenge and opportunity for the dental profession. Br. Dent. J. 2020, $229,282$. [CrossRef] [PubMed]

24. Islas-Granillo, H.; Borges-Yañez, S.A.; de Jesús Navarrete-Hernández, J.; Veras-Hernández, M.A.; Casanova-Rosado, J.F.; MinayaSánchez, M.; Casanova-Rosado, A.J.; Fernández-Barrera, M.Á.; Medina-Solís, C.E. Indicators of oral health in older adults with and without the presence of multimorbidity: A cross-sectional study. Clin. Interv. Aging 2019, 14, 219-224. [CrossRef] [PubMed]

25. Hilmer, S.N.; Gnjidic, D. Prescribing for frail older people. Aust. Prescr. 2017, 40, 174. [CrossRef] [PubMed]

26. Jacob, L.; López-Sánchez, G.F.; Carvalho, A.F.; Shin, J.I.; Oh, H.; Yang, L.; Veronese, N.; Soysal, P.; Grabovac, I.; Koyanagi, A.; et al. Associations between mental and oral health in Spain: A cross-sectional study of more than 23,000 people aged 15 years and over. J. Affect. Disord. 2020, 274, 67-72. [CrossRef] [PubMed] 